\title{
REDES SOCIAIS, MASCULINIDADE HEGEMÔNICA E VIOLÊNCIA: O MACHISMO COMO ELEMENTO (DES) CIVILIZACIONAL NO BRASIL
}

\author{
Marcio Jose Pereira iD1 e Luciane Cristina Gamas iD2
}

\section{Resumo:}

O controle das pulsões e o declínio da violência são elementos apontados por Norbert Elias como aspectos civilizacionais e que a partir do modelo da escada podemos evocar a elevação ou a decadência de grupos humanos de um nível para outro, uma vez que, a curva civilizacional não é um contínuo ininterrupto e pode sofrer em diferentes fases do processo. Descivilização significa uma transformação em direção oposta, uma redução nítida da simpatia pelo outro ou por seu grupo. Sopesando que $58 \%$ dos brasileiros possuem, ao menos, um perfil ativo em redes sociais, pretendemos analisar postagens atuais em páginas da rede social Facebook ${ }^{\mathrm{TM}}$ que remetam ou considerem como ponto de partida: a) promoção de comportamento machista; b) incitação a violência de gênero; c) manutenção de estereótipos vinculados a virilidade, e d) menosprezo a mulheres e grupos LGBTQIA+. Se a dominação masculina, como afirma Pierre Bourdieu, está ancorada no inconsciente e as estruturas simbólicas que ratificam esse inconsciente androcêntrico sobrevivem em homens e mulheres ainda hoje, buscaremos, em diálogo, com a teoria eliasiana tratar quais os mecanismos e instituições que possibilitam a manutenção desses costumes que não contribuem para a equidade de gênero e quais figurações carecem maior atenção para o reforço do autocontrole e para a determinação de políticas públicas para a promoção da equidade de gênero e o combate da violência ocasionada por comportamentos vinculados a uma masculinidade tóxica.

Palavras-chave: Redes Sociais; Masculinidades; Violência; (Des) civilização; Brasil.

\section{SOCIAL NETWORKS, HEGEMONIC MALE AND VIOLENCE: MACHISM AS A (DE)CIVILIZATION ELEMENT IN BRAZIL}

\begin{abstract}
:
The control of drives and the decline of violence are elements pointed out by Norbert Elias as civilizational aspects and that from the ladder model we can evoke the elevation or decay of human groups from one level to another, since the civilizational curve does not it is an uninterrupted continuum and can suffer at different stages of the process. Decivilization means a transformation in the

${ }^{1}$ Doutor em História pela Universidade Federal do Paraná. Professor do Departamento de História e do Mestrado Profissional em Ensino de História da Universidade Estadual de Maringá.

${ }^{2}$ Pedagoga pela Universidade Centro de Ensino Superior de Maringá. Graduanda em História pela Universidade Estadual de Maringá. Professora de Ensino Infantil na Secretária de Educação de Sarandi/PR.
\end{abstract}

Perspectivas em Diálogo, Naviraí, v. 08, n. 17, p. 215-234, maio/ago. 2021. 
opposite direction, a marked reduction in sympathy for the other or for your group. While considering that $58 \%$ of Brazilians have at least one active profile on social networks, we intend to analyze current posts on Facebook ${ }^{\mathrm{TM}}$ social network pages that refer or consider as a starting point: a) promotion of macho behavior; b) incitement to gender-based violence; c) maintenance of stereotypes linked to virility, and d) contempt for women and LGBTQ + groups. If male domination, as stated by Pierre Bourdieu, is anchored in the unconscious and the symbolic structures that ratify this androcentric unconscious still survive in men and women today, we will seek, in dialogue, with the eliasian theory to deal with the mechanisms and institutions that enable maintenance of those customs that do not contribute to gender equity and which figures need more attention to reinforce self-control and to determine public policies for the promotion of gender equity and the fight against violence caused by behaviors linked to a toxic masculinity.

Keywords: Social networks; Masculinities; Violence; (De) civilization; Brazil.

\section{Introdução}

- Senhor, as tristezas não se fizeram para os brutos, e sim para os homens; mas se os homens sentem demasiadamente, embrutecem. (Sancho

Pança ao seu senhor Dom Quixote)

Sociedades inteiras, antigas ou modernas, foram e são analisadas a partir da sua capacidade em manter aspectos civilizacionais. Essa manutenção está intimamente ligada ao controle das pulsões e ao declínio gradativo da violência; elementos apontados pelo sociólogo alemão Norbert Elias como fundamentais para um maior alcance do êxito civilizacional. Uma luta constante de sentimentos reativos, que ora são tolhidos pelo reflexo da vergonha (GOUDSBLOM, 2009), ora amparados pela criação de álibis para a agressão (GAY, 2002), sustentando um modelo de jogo cuja balança permanece por poucos instantes equilibrada.

A partir de um modelo de escada podemos evocar a elevação ou a decadência de grupos humanos de um nível para outro, uma vez que, entendemos a curva civilizacional não como um contínuo ininterrupto, mas como um processo que pode sofrer em diferentes fases do seu desenvolvimento. Logo, ao analisar determinadas figurações da sociedade brasileira, nos deparamos com elementos que consideramos descivilizacionais e que não promovem uma "boa sociedade". Mas o que é descivilização? Nada menos que uma transformação em direção oposta, uma redução nítida da simpatia pelo outro ou pelo seu grupo. 
Nesse sentido, entendemos que comportamentos vinculados ao conceito de masculinidade hegemônica (CONNELL; MESSERSCHMIDT, 2013) e de dominação masculina (BOURDIEU, 2017) como características descivilizacionais, pois, permissionam um conjunto de ações de estigmatização de grupos considerados minoritários, como mulheres, consideradas frágeis e não aptas para assumir postos sociais preponderantes e grupos LGBTQIA+, considerados anômalos por estarem a margem do pensamento hierárquico dicotomizado acerca dos gêneros. O machismo é a expressão de um conjunto de sentimentos reativos que são produzidos com o intuito de inferiorizar o gênero feminino e os gêneros considerados marginais promovendo várias formas de violência, seja física ou simbólica e que quando não controlados pelo conhecimento de uma educação para o respeito e para a equidade de gênero, "coloca-se entre os impulsos mais falíveis e mesmo mais assassinos que governam a ação humana, nestas situações, as pessoas não precisam ser loucas para dar livre curso a esses impulsos" (ELIAS, 2014, p. 29)

Considerando que o abandono da violência em detrimento ao diálogo é uma das características absolutas para o sucesso civilizacional, temos que ponderar que o desvio dessa outrora institucionalizada violência é uma das facetas modernas do comportamento não civilizado e que não há culpabilidade não humana nesse processo, recordemos o autor quando alega que ao se encontrar o volante de um automóvel, somente os próprios homens constituem perigo uns para os outros, portanto, entendemos que o retorno ou o não abandono dos comportamentos machistas, vinculados ao conceito de masculinidade hegemônica e de dominação masculina é um forte elemento (des) civilizacional.

No Brasil, é perceptível que, com o constante desenvolvimento dos sistemas de informação e de trânsito de dados via rede mundial de computadores (internet), subsídios sobre o que se entende atualmente como modo civilizado de comportamento podem ser facilmente acessados e aprendidos/assimilados, haja vista que, os conjuntos jurídicos e normativos (leis e conjuntos legais), os controles da pulsão, os mecanismos de manutenção desse controle civilizacional através de campanhas educacionais e formativas, circulam amplamente. Em suma, existe maior disponibilidade de acesso aos mecanismos educativos que outrora, mas isso não significa necessariamente um aumento do comportamento civilizado.

O poder do compartilhamento de imagens, memes, postagens, frases, vídeos e outros tipos de mídias que circulam pelas redes sociais tem uma taxa muito alta de alcance comunicativo, no Brasil, segundo pesquisa divulgada pelo Instituto Brasileiro de Geografia e Estatística (IBGE), sete (7) a cada dez (10) brasileiros estão conectados a rede mundial de computadores e desses, 58\% possuem, ao menos, um perfil ativo em redes sociais de acordo com o último levantamento da organização mundial We Are Social (Digital in 2020). Quando intencionamos essa análise no início de 2020 de acordo com o Social Media Trends 2019, da gigante em inteligência corporativa Rock Content, o Facebook ${ }^{\mathrm{TM}}$ era a rede social mais utilizada pelos brasileiros, porém, diante de uma quadro agravado de polarização política, da criação de perfis em "bolhas" e do alto 
número de banimentos de contas consideradas falsas; no último ano os brasileiros migraram para uma rede social do mesmo grupo financeiro, ocupando um tempo maior - das 3 horas diárias em média utilizadas com redes sociais com uma rede social considerada mais branda politicamente, o Instagram ${ }^{\mathrm{TM}}$.

Há um espaço bastante polêmico a ser considerado nessas pesquisas e um leitor desavisado poderia questionar-nos que a rede social mais usada é o Whatsapp ${ }^{\mathrm{TM}}$, porém, para as grandes corporações de Social Media, tanto o Whats, quanto o Messenger ${ }^{\mathrm{TM}}$ não são efetivamente redes sociais, mas sim aplicativos de comunicação imediata, com mais de 120 milhões de pessoas físicas cadastradas nesses serviços no Brasil, fora as contas corporativas e de


para o nosso estudo? Primeiro porque o mesmo é mais permissivo para a abertura de contas e de páginas cujo conteúdo expressado sejam teoricamente menos questionados do que em outras redes da mesma empresa como Twitter ${ }^{\mathrm{TM}}$ e Instagram $^{\mathrm{TM}}$, com políticas mais agressivas de bloqueio de postagens e sem espaços para "comunidades" e páginas de grupos específicos. Segundo porque a rede social idealizada pelo programador e empresário norte americano Mark Zuckerberg é a mais procurada para a instalação de páginas com conteúdo aberto sobre: a) promoção de comportamento machista; b) incitação a violência de gênero; c) manutenção dos estereótipos vinculados a virilidade; e d) menosprezo as mulheres e grupos Igbtqia+.

Objetivamos em diálogo, com a teoria eliasiana, analisar postagens de algumas páginas da rede social Facebook ${ }^{\mathrm{TM}}$ que enfatizam os comportamentos acima mencionados, nos interessa apontar quais os mecanismos e instituições possibilitam a manutenção desses costumes e como esse tipo de ação na rede mundial de computadores não contribuem para a equidade de gênero. Intencionamos ainda, avaliar quais figurações carecem maior atenção para o reforço do autocontrole, para a determinação de políticas públicas para a promoção da equidade de gênero e para o combate da violência ocasionada por comportamentos vinculados a uma masculinidade tóxica.

\section{Conceitos antigos e novos para problemas que atravessam os tempos}

Entre as relações humanas fundamentais, a necessidade de perpetuação das espécies faz com que as relações entre os sexos mantenham um contínuo de dependência mútua entre homens e mulheres, isso não significa que haja equilíbrio na balança de poderes entre ambas as partes. O que se percebe, historicamente, é uma quase absoluta supremacia dos homens em relação as mulheres, uma instituição do masculino, cuja virilidade consagra os homens ao poder e desconsideram os recursos de poder das mulheres possuem em um mesmo grupo social. Em suma, embora muitas mulheres operem a partir de um capital intelectual igual ou mais elevado que os homens, tendem a serem sub 
representadas, tanto na sua capacidade de produzir, quanto na sua suficiência em liderar. ${ }^{3}$

O passar dos anos fez com que as relações de poder entre os sexos se tornassem menos desiguais? Essa é a pergunta que qualifica a obra "Dominação Masculina", publicada em 1998, pelo sociólogo francês Pierre Bourdieu. O autor instigado pela sua própria inclusão nas estruturas históricas da ordem masculina se indaga como a dominação masculina sobrevive na sociedade da época, elencando formas de provar que a mesma se trata de uma construção social arbitrária de um conjunto de instituições como a família, a escola, a igreja e o próprio Estado, como agentes ratificadores da ordem já existentes. Nesse ponto, a sociedade dos finais do século XX retratada por Bourdieu, tal qual, a sociedade da segunda década do século XXI, se equiparam, por paradoxalmente, manter imutáveis determinados conjuntos de valores que levam a violência, transgressões e delitos contra grupos femininos e LGBTQIA+, mesmo possuindo conhecimento acerca de quão catastrófica é a insistência hegemônica da masculinidade.

É contra estas forças históricas de des-historicização que deve orientarse, prioritariamente, uma iniciativa de mobilização visando repor em marcha a história, neutralizando os mecanismos de neutralização da história. [...] É desejar que elas saibam trabalhar para inventar e impor, no seio mesmo do movimento social e apoiando-se em organizações nascidas da revolta contra a discriminação simbólica, de que elas são, juntamente com os (as) homossexuais, um dos alvos privilegiados, formas de organização e de ação coletivas e armas eficazes, simbólica e sobretudo, capazes de abalar as instituições, estatais e jurídicas, que contribuem para eternizar essa subordinação. (BOURDIEU, 2017, p. 5).

O problema da interpretação de Bourdieu é que - não intencionalmente o autor tenta inserir as mulheres em um movimento mais amplo, porém, mesmo dentro do "seio do movimento social" as mulheres não têm espaços para manifestar os seus projetos. Michelle Perrot (2015) é enfática quando pondera há um silêncio profundo do relato histórico, os primeiros historiadores não escreveram sobre "mulheres públicas", o silêncio das fontes também é profundo acerca das mulheres e a sua participação nos primeiros movimentos sindicais também é desprestigiado pelos homens que lideram o movimento, desqualificando a participação feminina, pois as mesmas não apresentam comportamento adequado para as greves. Para Perrot (2015, p. 169):

Na escala planetária, a globalização, pelo menos num primeiro momento, fragiliza os mais fracos, dentre os quais as mulheres, expostas à pauperização, à fome, às guerras nacionais étnicas que atingem mais de perto os civis, à AIDS galopante, mais grave na África, à prostituição cujas

\footnotetext{
${ }^{3}$ Esse fenômeno da sub representação feminina foi denunciado ainda no século XIX, quando a sufragista e abolicionista estadunidense Matilda Joslyn Gage, publicou o ensaio Woman as an inventor (The North American Review. Vol. 136, no 318, may 1883, p. 478-489, https://www.jstor.org/stable/25118273?seq=1\#metadata_info_tab_contents ). Nesse artigo pioneiro, ela aborda a relutância em dar crédito aos feitos realizados pelas mulheres em inúmeros campos, haja vista que, na maioria das vezes os homens "colhiam os louros" de descobertas puramente femininas. O termo "efeito Matilda" só passou a existir noventa anos depois, quando a historiadora Margaret Rossiter, teve acesso ao artigo e passou a escrever sobre o fenômeno do apagamento feminino das grandes descobertas históricas.
} 
redes se estendem, contradizendo a visão triunfante de uma sexualidade liberada. A história das mulheres é tão trágica quanto a dos homens.

O grande problema de muitas análises sobre a dominação do masculino é que elas insistem em descredenciar a luta feminina como um movimento capaz de fomentar sua própria "revolução". Se os homens permanecem os mesmos, as mulheres certamente mudaram, diminuíram os espaços, retomam o direito sobre seus corpos e aumentaram a resistência ao assujeitamento masculino.

Assim, a revolução sexual, que tentamos medir, está inacabada. Em verdade, é interminável. Nesse ponto, como em todos os outros, não existe "fim da história". É impossível, então, concluir o relato. Pode-se dizer "era uma vez". Invocar começos obscuros. Dizer o princípio. Mas não o "fim". História a continuar. História a fazer, também. (PERROT, 2015, p. 169).

Esse desenvolvimento não foi linear, mas avançou em surtos e regressões, e seguiu distintas direções em várias esferas da vida. É um processo que ocorre em vários campos da vida e em vários níveis: nas relações íntimas, na economia dos sentimentos, no curso da formação do Estado, na legislação e nos desenvolvimentos econômicos. Os processos parciais que constituem esse processo mais amplo não são independentes uns dos outros e devem ser vistos como um todo inter-relacionado. (ELIAS, 2009).

A construção da masculinidade hegemônica, perpassa o campo simbólico e modela atitudes, comportamentos e emoções a serem seguidas, aos que seguem esses modelos são atestados homens, aos que não alcançam os patamares estabelecidos pelo modelo de masculinidade, vivem sob o benefício da dúvida e sob a violência impetrada pelo não cumprimento das "normas". A masculinidade hegemônica é demarcada através da configuração atual da prática que legitima a posição dominante dos homens na sociedade e justifica a subordinação das mulheres e outras formas marginalizadas de ser um homem. Conceitualmente, a masculinidade hegemónica propõe-se explicar como e por que os homens mantêm papéis sociais dominantes sobre as mulheres e outras identidades de gênero que são percebidas como "femininas" em uma determinada sociedade. (CONNELL; MESSERSCHMIDT, 2013)

Historicamente, a falta de questionamento sobre o modelo assegura a manutenção da estrutura machista. Posturas oriundas do medievo reforçam o modelo de masculinidade, apesar de uma visível melhora em alguns aspectos do comportamento e da ação humana relacionadas ao convívio social, essa racionalização percebida por Elias, não alcançou completamente as questões de gênero: "a gradual racionalização e, mais, todo o processo civilizador, ocorrem sem dúvida alguma em constante ligação com as lutas de diferentes estratos sociais e outros grupamentos" (ELIAS, 1993, p. 235), ainda perdura uma espécie de veneração a níveis mais animais e automáticos da personalidade masculina, em suma, encarar a masculinidade como nobreza.

Tem-se a impressão de que a solidez, a resistência e o arraigamento do habitus social dos indivíduos numa unidade de sobrevivência aumenta à medida que se alonga e encomprida a cadeia de gerações em que certo habitus social se transmite de pai para filho. [...] os homens em posição 
de domínio eram os que traziam, tanto quanto podemos ver agora, a marca social de guerreiros e caçadores. As mulheres eram coletoras e ajudavam de muitas maneiras na ocupação central dos guerreiros e caçadores. (ELIAS, 1994, p. 173).

Embora, Elias (1993, p. 237) seja enfático ao ressaltar que "o que importa, o que determina a conduta, são os equilíbrios e conflitos entre as pulsões maleáveis e os controles construídos sobre as pulsões", essa "reificação" dos instintos primevos, tendem a serem mantidas como características positivas e de exclusividade masculina a valentia, a rudeza, a firmeza, a inteligência, a ausência da sensibilidade, logo, a imponência dessas "qualidades" são reforçadas e autoprojetadas nos homens. Um conjunto de normas, determinadas e seguidas de maneira quase imediata, são repassadas por meios sutis, como por mediação da cultura, que podem ser vistos em programas de televisão, filmes de sucesso, meios de comunicação, anúncios de produtos para fins de consumo, visto que as ações feitas nesses meios tendem a ser vistas como padrões comportamentais ideais (PAECHTER, 2009).

Os padrões comportamentais por sua vez reforçam estereótipos e personas que se mantém e se transformam em algo tóxico reforçando uma estrutura machista, abusiva, antissentimental, apresentando modelos e práticas características para cada momento como forma de superioridade de serem aceitos como homens viris, fortes, dominadores inclusive nas relações sexuais, aptos a apresentar uma força corporal elevada, uma distância emocional e equilíbrio, racionalidade coragem para arriscar e se aventurar. O conceito de "figuração" de Elias e seu modelo de relações parecem lançar luz sobre a problemática das relações de gênero, porém, precisamos abrir um parêntese importante antes de utilizá-lo, pois:

Planteada de tal forma la figuración, en la interpretación del autor, explica las razones y objetivos que los individuos buscan o encuentran en su relación con los otros, aun sin pensarlo en un sentido instrumental. Las relaciones sociales que se dan en las "figuraciones" que los individuos construyen en su interacción, representan, necesariamente, tensiones entre las diferentes posiciones de los individuos o grupos. Se Trata de equilíbrios fluctuantes de poder que explican la naturaleza dinámica de la realidad social, y en esa misma lógica, sugiere la transformación continua de las diferentes figuraciones. (MONTESINOS; MARTINEZ, 2001, p. 825826).

Analisar uma figuração como civilizada ou não, dentro de uma perspectiva processual pode-nos conduzir a uma percepção unificada, padronizada e muitas vezes errônea. Não podemos nos furtar de um posicionamento aqui, haja vista que, a noção de civilização corresponde a autoimagem do grupo dominante nas relações de poder de uma figuração, para os sujeitos produtores do conteúdo analisado nas redes sociais, autodenominados conservadores, a democratização dos gêneros e a ideia de um homem "efeminado" é uma grande prova que o "trem da civilização descarrilhou" e que uma retomada dos modelos anteriores seria a solução mais adequada para colocar "a sociedade nos eixos". Da mesma forma, mas em direção contrária, parte da sociedade entende que a manutenção 
dessas práticas de dominação masculina sejam elementos constitutivos de processos descivilizadores, pois, incita o aumento das manifestações violentas.

Las interdependencias humanas que dan forma a las "figuraciones" presumen captar las vinculaciones emocionales que reflejan el contacto de los individuos/face to face, además, supone que el intercambio social se proyecta por símbolos compartidos que permiten la identificación del yo y el nosotros. Necesariamente, las diferencias entre los individuos son sintetizadas mediante las estructuras simbólicas introyectadas que los hace parte de la colectividad. (MONTESINOS; MARTINEZ, 2001, p. 831)

Destarte, concordamos com Tania Quintaneiro, existem processos descivilizadores de várias amplitudes, o próprio Elias discorda da ideia que uma vez civilizados, sempre civilizados. Neste artigo, partimos da premissa que o machismo é um forte indício de Descivilização.

Essa contrapartida do processo civilizador comporta uma redução das interdependências e do autodomínio, e consequentemente um aumento no grau da violência praticada contra outros seres humanos, juntamente com um arrefecimento de sentimentos como a empatia. Durante um surto de descivilização, barbarização ou brutalização dá-se uma dilatação na necessidade de coerção externa; está em curso uma liberalização de instintos e pulsões antes reprimidos, ou um retrocesso a patamares mais altos de agressividade interpessoal do que vigorava no padrão prévio de pacificação. (QUINTANEIRO, 2010, p. 104).

Entendemos que esse processo de manutenção de estereótipos e a frequente potencialização de práticas de violência simbólica e de violência física contra mulheres e grupos LGBTQIA+ são fruto de uma maior flexibilização da violência e das condutas violentas no Brasil, principalmente pós 2018, com a polarização e radicalização política oriunda da disputa presidencial. Os números no Brasil são alarmantes e embora existam pesquisas, movimentos e políticas públicas alardeando sobre a questão, tal qual o tema dos Direitos Humanos, embora haja uma extensa legislação acerca da temática da proteção da mulher frente a violência, não averiguamos uma descendente nos números relacionados a feminicídio, assédio moral e sexual, estupros e condutas coercitivas contra mulheres no Brasil. Se civilizar-se é internalizar a norma dominante, no Brasil, há um grande contraste entre existir a lei e interpretá-la.

\section{O Facebook ${ }^{\mathrm{TM}}$ como espaço de disputa da balança de poder}

As lutas de emancipação e os ideais de igualdade que encontraram sua expressão ao largo da história não eram um fenômeno autocontido, mas sim parte de mudanças sociais maiores. Acompanharam os câmbios do mercado de trabalho (de uma sociedade industrial para uma de serviços) e o aumento do nível de educação das mulheres. Essa abertura gradativa que se consolidou de forma mais efetiva no pós Grande Guerra, exerceu influência sobre a lei (mudanças significativas nos direitos femininos) e trouxeram mudanças nas maneiras e padrões de controle emocional entre homens e mulheres. Um século depois, esperava-se que os homens possuíssem mais capacidades empáticas: amplitude de respeito pelos espaços ocupados pelas mulheres, de 
reconhecimento de sua existência no mercado de trabalho e em funções outrora desconsideradas femininas, entendimento dos desejos e ambições femininas, bem como, do direito de se reconhecerem realizadas ou não, independentemente se cumpriram papéis maternais, matrimoniais ou qualquer um desses estereótipos medievais sobre o papel social da mulher.

Identificamos que as três fontes básicas de manutenção do poder masculino sobre as mulheres ao longo do tempo: a) força física, b) conhecimento, c) capacidade de organização; não são mais relevantes, estão igualmente distribuídas e em todos os casos perderam a sua importância para efeito comparativo. Os três itens já foram balanceados, mas ainda há uma série de questões discrepantes relacionadas ao acesso ao mercado de trabalho, a valoração do trabalho feminino, a quantidade de horas trabalhadas (dupla/tripla jornada), a solidificação do espaço feminino na ciência e a vulnerabilidade dos corpos dada a violência expressiva contra mulheres.

São esses gatilhos que encontramos em inúmeras páginas das redes sociais, que reforçam o desbalanceamento e não produzem caminhos para a equidade de gênero, reforçando pontos negativos e conotações construídas séculos antes. O Facebook ${ }^{\mathrm{TM}}$ é uma das plataformas mais acessadas no mundo. Seu aparecimento contribuiu para uma reestruturação midiática e com a forma com que recebemos informações, sejam elas para o entretenimento ou para a politização. Esse modelo de rede social apresenta aos seus usuários conteúdos que vão de encontro com as publicações mais vistas e comentadas por eles, em um sistema algorítmico, que personaliza os anúncios, os grupos, as páginas, os perfis, que, em tese, mais se adequam com os interesses e itens de pesquisa de cada usuário.

A partir desse ponto algumas postagens chamam a atenção e viralizam na rede, tomando grandes proporções e assim sendo muitas vezes replicada sem muitos questionamentos. Visando entender algumas publicações e problematizá-las encontramos no Facebook $^{\mathrm{TM}}$ inúmeras páginas que nos apresenta um ideal de masculinidade, ou melhor dizendo padrões comportamentais que fazem do homem um "verdadeiro homem", essas postagens reforçam o caráter machista, homofóbico e assentimental do homem reforçando estereótipos que mantém e reestrutura uma masculinidade tóxica. Os perfis apresentam aos seus seguidores regras e orientações sobre como devem se portar e agir perante as situações que não são compreendidas como algo de macho, neste ponto as descrições dos grupos em sua grande maioria apresentam um padrão em comum, regras como: a) NÃO pode ser fraco, b) NÃO se permite mulheres, gays e esquerdistas, c) concordar que a comunidade serve pra reforçar a masculinidade do homem que está perdida na "modernidade", d) que a heteronormatividade é o requisito para entrar nesses grupos, e) somente podem participar homens que buscam reforçar a honra, lealdade, virilidade e a sua transformação em um líder nato (alpha), esses pontos são constantemente reforçados, essas regras apresentam uma forma de selecionar e enquadrar os seguidores, tudo que foge do que é considerado o perfil de macho é terminantemente proibido.

Não foi possível identificar o número de perfis/comunidades que tem no seu escopo motivações relacionadas a ensinar o homem a ser homem, resgatar 
a masculinidade perdida, promover conteúdo machista, homofóbico e misógino ${ }^{4}$, páginas que incitam a violência de gênero e o menosprezo às comunidades Igbtqia+, são imensuráveis sem estar em posse de um algoritmo próprio ou de um relatório da própria rede social. Iremos elencar algumas que consideramos casos clássicos do que entendemos por uma figuração social que mantem, reforça ou remete a um surto descivilizacional.

Figura 1 - Sentimentalismo masculino x feminino

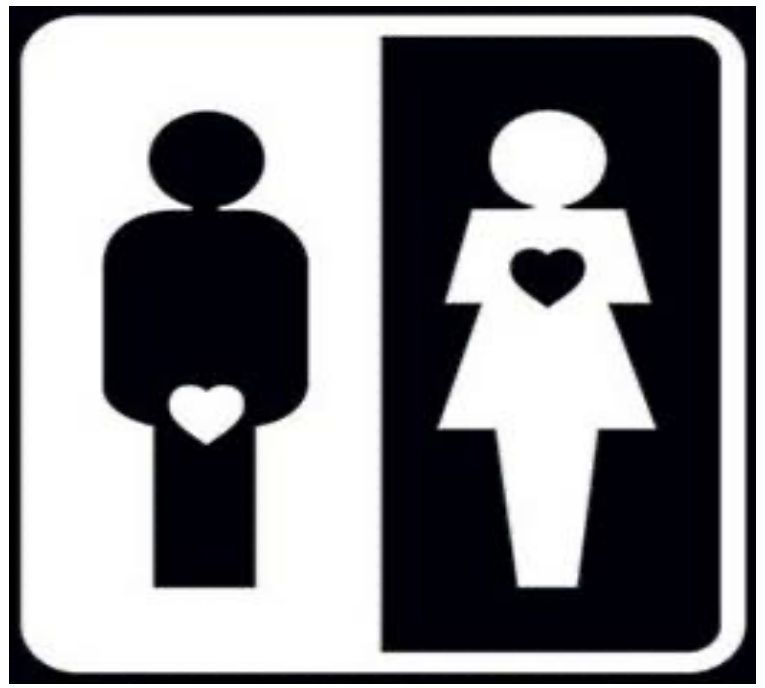

Fonte: Página Homem Raiz 4.0 Postagem de Junho de 2019 Disponível em: https://www.facebook.com/HomemRaiz4.0

A típica associação ao sentimentalismo feminino e a racionalização masculina, nesse caso a imagem está demonstrando um aspecto ainda mais violento de uma característica fisiológica, o sentimento único masculino é o instinto sexual, logo, não poderá existir uma relação entre homem e mulher que não passe pelo crivo do desejo sexual. Não estamos descartando características biológicas importantes, como a maior capacidade feminina de transformar sentimentos em linguagem, porém, a manifestação de comentários de pouco valor formativo e que ratificam discursos de violência física e simbólica.

\footnotetext{
${ }^{4}$ Cabe-nos ressaltar que esse não é um fenômeno isolado do Brasil e que ele não é fruto único e exclusivo da transição de poder político no país que permissionam a publicização de conteúdos misóginos, machistas, violentos, racistas etc., que poderiam colocar em risco até a constatação moral do ser cidadão. Pesquisas recentes, como do antropólogo Marco Julian Martinez Moreno da Universidad Nacional de Colombia, "Ser macho neste país é coisa de macho": a culturalização da masculinidade e sua relação assimétrica com a igualdade», Anuário Antropológico, v.41 n.2, 2016, p. 33-56. (https://journals.openedition.org/aa/1795 ); do historiador britânico Mark Sedwick, Contra o mundo moderno (2020), publicado no Brasil pela editora Âyiné; do etnógrafo estadunidense Benjamin Rafael Teitelbaum, Guerra pela eternidade: o retorno do tradicionalismo e a ascensão da direita populista (2020), publicado no Brasil pela Editora da Unicamp; da antropóloga brasileira Rosana Pinheiro-Machado, da Barth University (UK) que tem estudado temas ligados as masculinidades e ao masculinismo. Todas as obras e autores/as citados tem investigado como o pensamento tradicionalista tem sido retomado como a faceta mais conservadora da direita radical mundial, bem como, esse pensamento radicado em sujeitos como Donald Trump, Jack Donovan, Steve Bannon, Olavo de Carvalho, Alexandre Dugin etc. O tribalismo masculino é só uma das questões que envolvem os adeptos, que ainda convivem com a continua descrença na modernidade, exaltam um passado religioso sem espaço para a livre interpretação das escrituras, rejeitam a democracia secular, a igualdade econômica entre povos e sexos e, traçando um paralelo rápido com a temática do artigo, acreditam que as mulheres não tenham nenhum papel social no mundo, são abertamente anti-gays, mas mantem relações sexuais com outros homens como uma defesa a um ideal masculino, por fim, em contraposição franca as pessoas transgênerose a teoria queer, defendem que gênero é natural e portanto imutável.
} 
O equilíbrio de poder entre os sexos irá também variar a favor dos homens de acordo com o grau em que estes dispõem, em relação as mulheres, de mais hipóteses de ações unificadas, e sempre que os homens monopolizam o acesso e o controlo das principais determinantes das oportunidades sociais, em especial, na economia e no Estado. Além disso, em qualquer sociedade, quanto mais acentuadas forem as formas do domínio masculino, maior será a tendência para prevalecer a rigorosa segregação entre os sexos. (DUNNING, 1992, p. 392).

O Brasil já é naturalmente conhecido pela sua cultura do estupro ${ }^{5}$ e por inúmeros casos de omissão de socorro às vítimas de violência doméstica. Inúmeras justificativas de estupro no Brasil passam pela clássica manifestação "ela estava procurando", "ela vestia uma roupa curta", "o que ela estava procurando essas horas?". Inventamos no Brasil uma terminologia até hoje inexistente em qualquer código do Direito Internacional, o "estupro culposo", fato que elevou a hashtag \#estuproculposonaoexiste aos trending tops do Twitter $^{\mathrm{TM}}$, Facebook ${ }^{\mathrm{TM}}$ e Instagram ${ }^{\mathrm{TM}}$, logo após a emissão do parecer jurídico no caso Mariana Ferrer.

Figura 2 - Charge de Nando Motta - Sobre o absurdo caso Mariana Ferrer

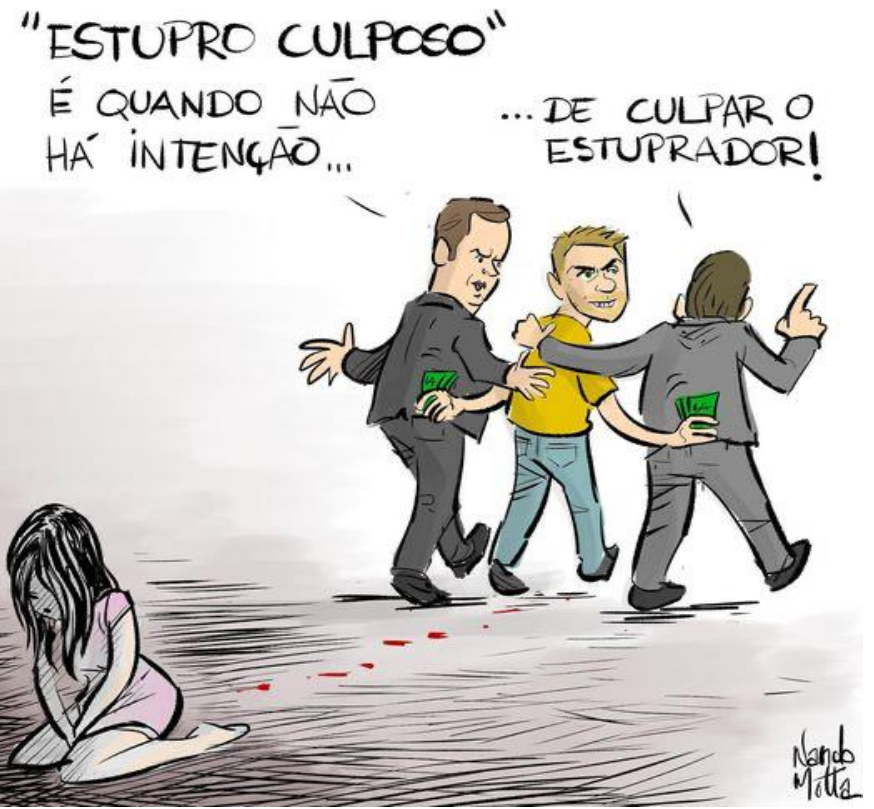

Fonte: Desenhos do Nando. Disponível em:

https://www.facebook.com/desenhosdonando/photos/a.1615515068716641/2848314012103401/

\footnotetext{
${ }^{5}$ A cultura do estupro é uma terminologia que reflete sobre a banalização e normalização desse crime por uma determinada sociedade que compactua e estimula essa cultura de inúmeras formas, ratificando a objetificação da mulher, culpabiliza a vítima e ao não considerar algumas práticas como anormais. Estudos atuais desenvolvidos no Brasil apontam que a cultura do estupro, enquanto um subproduto do patriarcado, no Brasil não acompanham a racionalidade/civilidade, uma vez que, padrões de comportamento violento contra mulheres e grupos LGBTQIA+, ausência de punição para os estupradores e conivência com a transferência da culpa para as vítimas pelo sistema judiciário, não permissionam uma transformação cultural efetiva e um descenso no número de estupros (aproximadamente mais de 500 mil tentativas de estupros, com cerca de $10 \%$ de registros efetivados, segundo o Atlas da Violência 2020), ver: ENGEL, Cíntia Liara. As atualizações e a persistência da cultura do estupro no Brasil. Rio de Janeiro: IPEA, 2017SANTOS, Tainá Bettim dos; BARCELLOS, Olinda. Cultura do estupro no Brasil: origem e fundamentos em uma sociedade patriarcal. Seminário Internacional Demandas Sociais e Políticas Públicas na Sociedade Contemporânea, 2019. SEGATO, Rita. La estructura de género y el mandato de violación. In: GUZMAN, Alejandra de Santiago (org). Mujeres Intelectuales: feminismos y liberación em América Latina y el Caribe. Buenos Aires: CLASCSO, 2017. SOUSA, Renata Floriano de. Cultura do estupro: prática e incitação à violência sexual contra mulheres. Revista Estudos Feministas, v. 25, n. 1, p. 9-29, 2017.
} 
As mulheres tendem a se sentir desconfortáveis em organizações dominadas por homens, não pela sua incapacidade de operacionalizar, de organizar e produzir, mas pelo constante e muitas vezes explícito, abuso moral e sexual a elas destinados. Como produzir com qualidade se não há certeza que o destaque do seu trabalho seja efetivamente pela sua ação dentro da organização e não pelo delineamento do seu corpo? Para muitos homens em cargos de chefia, essa validação da masculinidade é natural e torna o ambiente mais competitivo, porém, não são significativas para a questão da equidade salarial, de postos de trabalho e do preenchimento de cargos de liderança.

Em um país com número alarmante de casos registrados ${ }^{6}$ - imaginem os não denunciados - um conjunto de ações, de políticas públicas, de educação sexual, de pautas sobre equidade de gênero são mais que necessárias, inclusive sua ampla exposição nas redes sociais. Porém, notamos uma inação nesse sentido por parte das pastas vinculadas ao governo federal e um crescimento vertiginoso de páginas e conteúdos na web que enaltecem formas de pensar cuja obsolescência é nítida em nossa sociedade atual. Consideramos algumas postagens como desserviço educacional, tal qual argumenta a jornalista Renata Rode em seu artigo "Homens pensam com a cabeça de baixo", na sua coluna Mulher Comportamento do portal UOL, pois justificam de maneira explícita comportamentos criminosos, uma postagem recorrente para justificar o instinto masculino vem de um livro escrito pelo professor, psicólogo e jornalista Felipe Pena, que publicou o romance "O marido perfeito mora ao lado", pela editora Record, vejamos uma afirmação do autor para a página Mulher UOL: "A verdade é que para o homem é difícil resistir a uma mulher de minissaia, pois, nesse momento, o neurônio masculino se descobre sozinho no cérebro, já que todos os outros fogem para a festa lá embaixo.", ou ainda, a afirmação para o mesmo canal, do escritor e jornalista Ismael de Araújo, autor do "Manual do Xavequeiro", publicado pela Editora Matrix: "O homem tem de conviver com os hormônios, a pressão social e o impulso para fingir que não pensa com a cabeça de baixo. É uma luta constante da razão contra o tesão".

Aqui todo esforço de Elias $(1993 ; 1994)$ ao problematizar o processo civilizador se esvai, pois, há um desvio nítido dos elementos constitutivos de uma capacidade de racionalização e de controle das pulsões. Parece-nos que existe um desejo tácito de justificar as ações masculinas pelo instinto, devolvendo ao homem o "direito" de criar álibis para agredir. É perceptível um não esforço dessas páginas em refletir sobre a humanidade do outro.

\footnotetext{
${ }^{6}$ No Brasil existem algumas instituições que geram dados sobre feminicídio oficialmente, como o Conselho Nacional do Ministério Público, que fornecem dados sobre inquéritos que apuram crimes de feminicídio. O Ministério da Saúde, que fornecem dados acerca da mortalidade feminina de acordo com o princípio do CID-10. Ministério da Justiça, com seu largo banco de dados sobre feminicídio (desde 2015) e outros crimes violentos contra mulheres com classificações anteriores a Lei do Feminicídio (13.104/2015). As Secretárias de Segurança Pública de inúmeros estados da federação mantem bancos de dados regionais. O IBGE, com a Pesquisa Nacional por Amostra de Domicílios (PNAD). E, a que consideramos mais densa e completa para analisar dados referentes as questões abordadas nesse texto, que são oriundas do Instituto de Pesquisa Econômica Aplicada (IPEA), vinculado ao Ministério da Economia, responsável pela publicação do Atlas da Violência. Cabe ressaltar, em tempo, o papel de inúmeros institutos, organizações nãogovernamentais e secretarias municipais que realizam coleta de dados e fornecem registros locais importantes sobre a violência de gênero e as facetas agressivas da manutenção do machismo.
} 


\section{Figura 3 - Desconstruir a luta feminista \\ Orgulho Hétero \\ 27 de dezembro de 2015 - 8}

\section{ESSA É UMA LAVADORA}

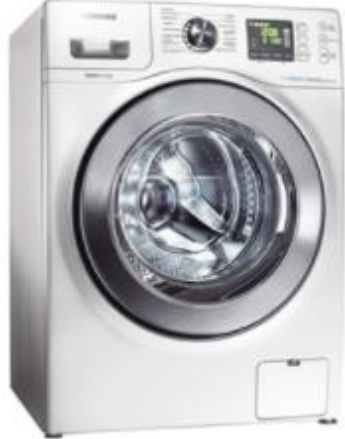

\section{E ELA JÁ FEZ MAIS PELAS MULHERES OUE TODO O FEMINISMO JUNTO.

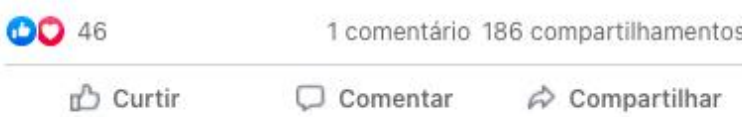

Fonte: Orgulho Hétero. Disponível em:

https://www.facebook.com/orgulhoheterocomh/photos/a.1666779540260166/1666779503593503/

A descaracterização da luta feminista também é uma ferramenta muito utilizada, atacar o movimento e todas as conquistas por ele realizadas ao longo dos anos parece ser uma estratégia muito profícua, haja vista o enorme compartilhamento de ideias, inclusive de mulheres, nesse post, foram 186 compartilhamentos, com cerca de $10 \%$ de perfis femininos compartilhando a imagem. Em um cálculo superficial dessa publicação facilmente alcançou meio milhão de usuários brasileiros sem precisar de impulso pago. Precisamos abrir um parêntese importante nesse ponto, não podemos analisar mulheres e mulheres feministas como uma figuração única, os interesses das mulheres representam um conjunto muito diverso de interesses em termos de classe, raça, etnia, faixa etária etc.

Essa adoção de um padrão comportamental de algumas mulheres em relação ao machismo é explicada por Dunning, Murphy e Willians:

Isto traduz-se, por um lado, na tendência destas comunidades para atingirem um grau comparativamente elevado de violência masculina em relação a mulher e, por outro, no facto de os seus elementos masculinos não estarem sujeitos, de forma consistente, a pressão feminina de «suavização». Com efeito, na medida em que as mulheres, em semelhantes comunidades, crescem de forma a serem elas próprias relativamente agressivas e valorizando muitas das características macho dos seus homens, as inclinações agressivas tendem a ser conciliadas. [...] Um dos efeitos desse processo é a atribuição de prestígio aos membros do sexo masculino de comprovada capacidade para lutar. (DUNNING; MURPHY; WILLIAMS, 1992, p. 374). 
As práticas machistas e manifestações da dominação masculina são tão violentas que elas perpetuam um sistema que subjuga os próprios homens, elencando características físicas, de caráter, de capacidade organizacional e de ímpeto pela violência. $O$ culto a figuras masculinas fortes, musculosas, militares, sem sentimentos, com alta capacidade de empunhar armas e utilizar de meios violentos para obter seus objetivos é uma máxima nessas comunidades. Figuras emblemáticas do cinema como o ex-fuzileiro naval John Rambo, o lendário ator Chuck Norris em sua franquia de ação Comando Delta, o mestre das gambiarras McGyver, a frieza de Thommas Shelby, a virilidade do Rei Leonidas, líder dos 300 de Esparta, são invariavelmente utilizadas para enaltecer o "macho de verdade", o "verdadeiro homem", etc. Essa dinâmica não ocorre sem uma contrapartida crítica, atacando as masculinidades emergentes e taxando-as de perversão, descaminho e em alguns grupos, fruto da "ditadura gay". Vejamos abaixo um comparativo divulgado na página Macho Véi Cristão e compartilhado pela página Mudando o Brasil para a Direita:

Figura 4 - Masculinidades Raiz x Masculinidades Emergentes

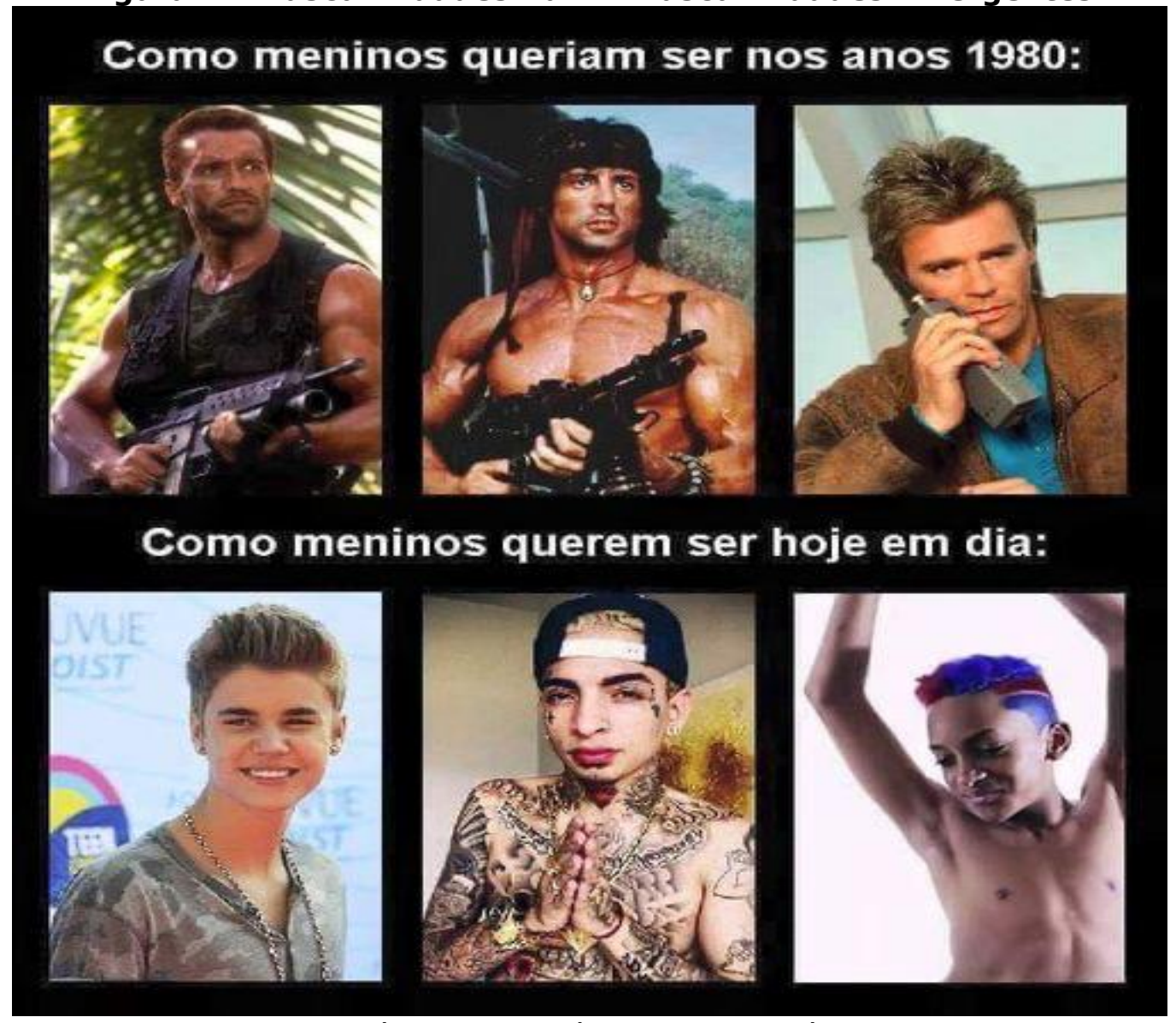

Fonte: Página Macho Véi Cristão. Disponível em:

https://www.facebook.com/machoveicristao/photos/1074673895939193

A cultura patriarcal oprime a todos nós, é indubitável seu poder destrutivo na sociedade atual, quando condiciona crianças a se desfazerem de características da própria infância em nome de uma identidade de gênero 
desejada pelos pais. Para não sofrer consequências como castigos físicos e verbais, algumas buscam um comportamento que não necessariamente reflete o seu desejo, condição ou forma de pensar. Para escapar das supostas peculiaridades femininas destacadas por parte da sociedade, meninos e meninas buscam de formas diversas alcançar a castração dos afetos e omitirem qualquer nível de sentimento ou de ação física ou mental que comprometa o rótulo da sua sexualidade.

A tradição machista consagra o falo como arma masculina e a sua exaltação como elemento que dá molde a virilidade, basta-lhe o falo, ereto e pronto, para que a dominação aconteça. Essa percepção é tão mirabolante do ponto de vista psicanalítico e histórico, que não haveria possibilidade empírica de um homem usar o próprio falo como argumento em uma discussão, mas eis que o administrador da página Orgulho Hétero (pouco mais de 1700 seguidores) alertar o seguinte:

Amigo, quando uma feminista começar a te encher o saco com um monte das supostas vantagens de ser mulher, e ficar cantando superioridade, vire-se para ela, levante a cabeça e diga: Eu posso mirar para urinar e você não pode! Pronto, com isso você derrubou por terra todo o mundo dela e jogou ela na fossa, não importa o que ela tente dizer depois, ela não terá mais argumento, se ela tentar usar de Ad hominem, apenas repita a frase. Se ela disser que você não sabe argumentar, diga que não precisa pois você pode mirar e ela não pode, isso será mais que suficiente para fazer qualquer feminista ir parar no psicólogo. (FACEBOOK, 2016).

Se a arma natural do homem é o falo, o homem de bem (existe uma discussão popular muito obtusa sobre o significado dessa expressão no Brasil) também deve portar um meio de defesa significativo a sua qualidade de macho: a arma de fogo. Com acesso facilitado, nos últimos dois anos, o Brasil que figura na lista dos países mais violentos do mundo e com uma taxa de homicídios altamente qualificada, aumentou em $120 \%$ o número de registros de armas entre 2019 e 2020, estamos falando de aproximadamente 200 mil novas armas adquiridas em condições legais, não estamos estimando o trânsito de armas em caráter ilegal no país, que no último Anuário Brasileiro de Segurança Pública registrou mais de 70 mil armas localizada fora dos registros legais do Exército Brasileiro e da Polícia Federal. Se considerarmos o tráfico paulista e carioca, as milícias que atuam em comunidades ao largo do país e as quantidades expressivas de armas negociadas em regiões de garimpo e de grilagem de terras no Brasil, o número é assustador.

Esse enaltecimento do poder de fogo e a sua facilitação jurídica conduz uma enormidade de sujeitos a manterem sob sua posse uma arma de fogo, sem entrar o mérito da capacidade psicológica de portar uma arma, entendemos que a ampliação do acesso é responsável em grande parte do aumento de mortes de mulheres por ex-maridos, ex-namorados, ex-companheiros etc. Em outra página do Facebook ${ }^{\mathrm{TM}}$, com o mesmo título da página anteriormente investigada, encontramos esse post sobre a importância do "homem de bem" estar armado: 
Figura 5 - Armas contra os homens que não são de bem

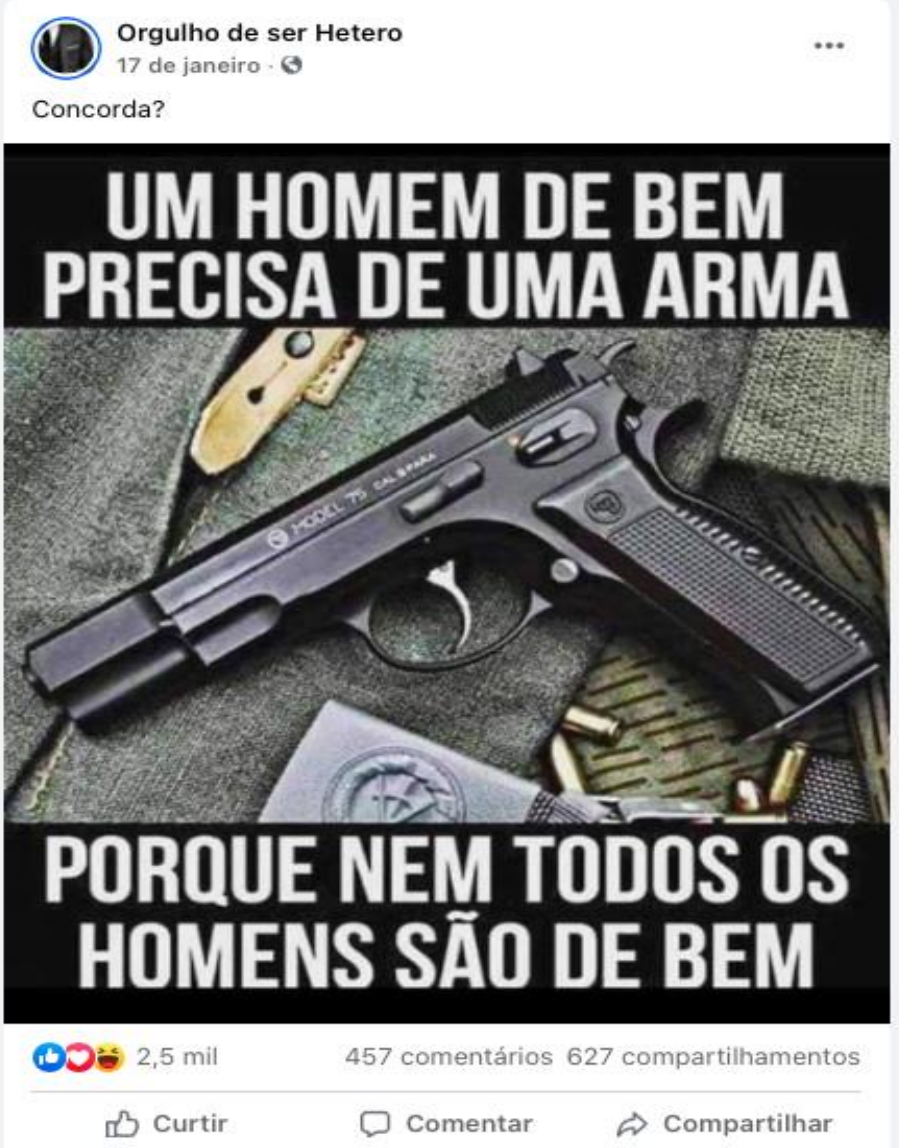

Fonte: Orgulho Hetero. Disponível em:

https://www.facebook.com/OrgulhodeserHetero/photos/a.2240010236069791/5034170923320361/

O número de compartilhamentos é muito expressivo e ressoa de maneira muito negativa, haja vista que, uma das tentativas de retomada do patriarcado é reviver o pather families, em suma, a figura masculina central das grandes famílias, o provedor, aquele que protege, que gerencia a distribuição do dinheiro, dos alimentos e dos afazeres, trata dos arranjos matrimoniais para as filhas e zela pelo bom nome familiar. Elias e Dunning, no capítulo VI, da obra A busca da excitação, ao refletirem sobre a dinâmica dos grupos desportivos, também questionam o termo patriarcado como conceito para compreender o equilíbrio de poder entre os sexos, o autor sugere que andrárquico, ou seja, dominado por homens, e ginárquico, ou seja, dominado por mulheres, são termos mais concisos para uso na análise de relações entre os sexos do que patriarcal, significando "homens em sua capacidade de pais" e matriarcal significando "mulheres na qualidade de mães". Além disso, seu conceito de equilíbrio de poderes ou relações de poder permitem que os sociólogos percebam os diferenciais de poder entre grupos de mulheres e homens, ou entre grupos de mulheres, ou em relacionamentos entre homens e homens como "sombras e graus", em vez de em termos de polaridades estáticas (ELIAS; DUNNING, 1992, p. 289). 
Haveria ainda uma discussão teórica bastante importante sobre o entendimento de Norbert Elias em relação a como o poder do Estado emerge como um poder tipicamente masculino que se organiza e se institucionaliza como forma de dominação social, por hora, concordamos com a socióloga Jennifer Hargreaves que:

O conceito de civilização incorpora uma visão galante de masculinidade, tratando o estado como um mecanismo habilitador, sem examinar seu papel de forma sistemática e desconsiderando as formas como o estado tem tratado os sexos desiguais e as complexidades e características contraditórias da hegemonia do sexo masculino. O termo 'estado' é usado descritivamente na sociologia figuracional, mas precisa ser examinado para que possamos entender seu caráter de gênero e se é em algum grau autônomo dos interesses dos homens ou de uma expressão integral deles. Já que Elias não aborda o relacionamento entre moralidade, justiça e poder, a falha em incluir gênero em uma consideração do estado e postular a ideia de que o estado é um facilitador de relações melhoradas a longo prazo entre os sexos pode ser visto como uma desculpa para não se envolver em uma luta para mudar as coisas agora. (tradução nossa ${ }^{7}$ ) (HARGREAVES, 1992, p. 171).

A ideia de desigualdade harmoniosa, ratifica a posição de inferioridade e subordinação da mulher em relação ao homem e mantem desestabilizado o equilíbrio de poder, as oportunidades de distribuição de poder, as nuances e graus de poder dos grupos humanos, logo, embora exista nessas gradações elevados níveis de interdependência, a estrutura social que está consolidada mantêm os privilégios masculinos ante aos apelos femininos por um pareamento da balança de poder. ${ }^{8}$

\section{Considerações finais}

Refletindo sobre a mudança do equilíbrio de poder entre os sexos, podemos dizer que não se trata apenas da igualdade como norma última, especialmente no sentido de que as mulheres teriam que se apropriar do

\footnotetext{
${ }^{7}$ Elias and Dunning, however, give little attention to the role of the state in contemporary society and say nothing about how state power emerged as male power and has become an organized and institutionalized form of social dominance. The concept of civilization embodies a gallant view of masculinity, treating the state as an enabling mechanism without examining its role systematically and disregarding ways in which the state has treated the sexes unequally and the complexities and contradictory features of male hegemony. The term 'state' is used descriptively in figurational sociology, but it needs examination so that we can understand its gendered character and whether it is to some degree autonomous of the interests of men or an integral expression of them. Since Elias does not address the relationship between morality, justice and power, the failure to include gender in an account of the state and to posit the idea that the state is a facilitator of longterm improved relations between the sexes could be viewed as an excuse for not engaging in a struggle to change things now. (HARGREAVES, 1992, p. 171)

${ }^{8}$ Existe um campo profícuo no Brasil sobre masculinidades e mídias sociais, que se desenvolve de maneira muito expressiva em várias frentes disciplinares, infelizmente, dado aos objetivos do artigo e a extensão limitada do texto não nos foi possível realizar um estado da arte com muita profundidade, porém, gostaríamos de deixar algumas indicações de autores/as para futuros debates, ver: BALISCEI, João Paulo; DA CUNHA, Susana Rangel Vieira. "Faça como homem": cultura visual e o projeto de masculinização dos meninos. TEXTURA-Revista de Educação e Letras, v. 23, n. 54, 2021. FELIPE, Delton Aparecido; TAKARA, Samilo. Narrativas midiáticas sobre a sexualidade: Educação, diferenças e problemáticas à formação docente. Práxis Educacional,[S. I.], v. 16, n. 39, p. 138-160, 2020. GROHMANN, Rafael. Não sou/ não curto: sentidos midiatizados de masculinidade, feminilidade e classe social nos discursos de apresentação do aplicativo Grindr. Sessões do Imaginário, v. 21, n. 35, Porto Alegre, 2016. PADILHA, João Filipe \& RODRIGUES, André Iribure. As Representações das Masculinidades na Publicidade: os comerciais da campanha "Você é o cara. Você é o Kaiser". Anais do Intercom. São Paulo, 2016. ZANELLO, Valeska. Masculinidades, cumplicidade e misoginia na "casa dos homens": um estudo sobre os grupos de whatsapp masculinos no Brasil. Curitiba: CRV, 2020.
} 
comportamento e do habitus dos homens, sem mudanças no sentido inverso, afetando os homens. Investigando mudanças no equilíbrio de poder, precisamos também investigar a avaliação do comportamento e das qualidades relacionadas às mulheres, e do comportamento relacionado aos homens e masculinidade. Isso se resume à questão de quem tem o poder de definir o que é e o que não é altamente valorizado na sociedade e o que é estimado ou subestimado socialmente.

Para colocar a perspectiva de Elias e Scotson (2000) nos termos mais simples possíveis: as mudanças no equilíbrio de poder entre os sexos não podem ser entendidas sem levar em conta o desenvolvimento mais amplo da sociedade. Por isso, devemos considerar não só o estágio de formação do Estado, o desenvolvimento do mercado de trabalho e a proteção prevista em lei, mas também a questão de quem tem o poder de definir quais são as formas de comportamento e de expressão emocional, são ou não valorizados, quais aspirações são permitidas a quem e que nível de controle emocional é exigido de quem. O estabelecido pode ditar as regras, mas se forasteiros de outrora conquistarem o poder, eles também farão ouvir sua voz, e também vão participar do estabelecimento das regras do jogo social, e forçar o estabelecido a aceitar esse fato. Este processo está agora em andamento e não ocorre sem tensão e conflito. Isso leva a conflitos entre e dentro dos indivíduos que fazem parte dos processos por meio dos quais o equilíbrio de poder se torna menos desigual. (ELIAS; SCOTSON, 2000)

Refletindo essa conclusão a partir de Elias e Dunning (1992), poderíamos pensar que uma das consequências suplementares a esse embate dicotomizado entre masculino/feminino é que os valores machistas se inclinam no sentido de um papel mais importante na identidade masculina nas condições sociais em que os confrontos são frequentes e o equilíbrio de poder se orienta com mais clareza a favor dos homens, porém, na medida em que as relações sociais se apaziguam, as conjeturas de poder das mulheres aumentam, a segregação sexual desaparece e as tendências macho dos homens deslocam-se no sentido da civilização.

Parece simples e uma questão de tempo, gradativamente a balança de poder se alinharia e a equidade se tornaria uma realidade, mas num país que registra um caso de feminicídio a cada sete horas ${ }^{9}$, é preciso reforçar através de todos os meios, formas de fortalecer o enfrentamento da violência doméstica, de gênero e contra a população LGBTQIA+ no Brasil, facilitar o acesso às redes de apoio existentes e criar novas se necessário, estabelecer metas de educação e de um ensino que não seja omisso em relação as questões vinculadas a sexualidade, ao combate das atitudes vinculadas a masculinidade hegemônica e aos comportamentos, por nós entendidos, como descivilizados. Somente dessa forma poderemos encontrar uma figuração possível para o que Elias (2009, p.46) chama de "equilíbrio imputável entre os impulsos emocionais e os impulsos

\footnotetext{
${ }^{9}$ Dados obtidos no Atlas da Violência 2020 do Instituto de Pesquisa Econômica Aplicadas, vinculado ao Ministério da Economia do Governo Federal (https://www.ipea.gov.br/atlasviolencia/download/24/atlas-da-violencia-2020 ). Alguns desses dados também podem ser acompanhados em outros canais vinculados ao Fórum Brasileiro de Segurança Pública (FBSP), através do link https://forumseguranca.org.br/ e também no Monitor da Violência mantido pela Núcleo de Estudos sobre a Violência (NEV) da Universidade de São Paulo (USP) através do link https://nev.prp.usp.br/projetos/projetos-especiais/monitor-da-violencia/ .
} 
contrários do controle-emocional, em suma, a condição de auto regulação de suas emoções para outros seres humanos". Por fim, que se estabeleçam relações sociais que transpassem pelos conceitos de valoração da dignidade humana, empatia com o outro e respeito independente de classe, raça, etnia, sexo, orientação sexual ou identidade de gênero.

\section{REFERÊNCIAS}

BOURDIEU, Pierre. A dominação masculina Trad. Maria Helena Kuhner. 14 ed. Rio de Janeiro: Bertrand Brasil, 2017.

CONNELL, Robert W.; MESSERSCHMIDT, James W. Masculinidade hegemônica: repensando o conceito. Revista Estudos Feministas, v. 21, n. 1, p. 241-282, 2013. Disponível em: https://www.scielo.br/scielo.php?pid=S0104026X2013000100014\&script=sci_arttext\&tlng=pt Ultimo acesso: 30 maio 2021

DUNNING, Eric; MURPHY, Patrick; WILLIAMS, John. A violência dos espectadores nos desafios de futebol: para uma explicação sociológica. In: ELIAS, Norbert \& DUNNING, Eric. A busca da excitação. Trad. Maria Manuela Almeida e Silva. Lisboa: DIFEL, 1992.

DUNNING. Eric. O desporto como uma área masculina reservada: notas sobre os fundamentos sociais da identidade masculina e as suas transformações. In: ELIAS, Norbert \& DUNNING, Eric. A busca da excitação. Trad. Maria Manuela Almeida e Silva. Lisboa: DIFEL, 1992.

ELIAS, Norbert \& DUNNING, Eric. A busca da excitação. Trad. Maria Manuela Almeida e Silva. Lisboa: DIFEL, 1992.

ELIAS, Norbert. O processo civilizador. Formação do Estado e Civilização. Trad. Ruy Jungmann. Rio de Janeiro: Jorge Zahar Editora, 1993, v.2.

ELIAS, Norbert. A sociedade dos indivíduos. Trad. Vera Ribeiro. Rio de Janeiro: Jorge Zahar Editora, 1994.

ELIAS, Norbert \& SCOTSON, John L. Os estabelecidos e os outsiders.

Sociologia das relações deo poder a partir de uma pequena comunidade. Trad. Vera Ribeiro. Rio de Janeiro: Jorge Zahar Editora, 2000.

ELIAS, Norbert. Introdução à sociologia. Lisboa: Edições 70, 2014.

ELIAS, Norbert. Sobre os seres humanos e suas emoções: um ensaio sob a perspectiva da sociologia dos processos. In: GEBARA, Ademir \& WOUETRS, Cas. $O$ controle das emoções. João Pessoa: Editora da UFPB, 2009.

FACEBOOK. Orgulho de ser hétero. Vantagens de ser homem. 25 de janeiro de 2016. Disponível em: https://www.facebook.com/orgulhoheterocomh Último acesso: 30 de maio de 2021. 
HARGREAVES, Jennifer. Sex, Gender and the Body in Sport and Leisure: Has There Been a Civilizing Process? In: DUNNING, Eric \& ROJEK, Chris. Sport and leisure in the civilizing process. Critique na Counter-Critique. London: Macmillan Academic and Professional Ltd, 1992.

GAY, Peter. O século de Schnitzler: a formação da cultura da classe média (1815-1914 Trad. S. Duarte. São Paulo: Companhia das Letras, 2002.

GOUDSBLOM, Johan. A vergonha: uma dor social. In: GEBARA, Ademir \& WOUETRS, Cas. 0 controle das emoções. João Pessoa: Editora da UFPB, 2009.

MONTESINOS, Rafael \& MARTÍNEZ V, Griselda. Los usos sociológicos de Norbert Elias. Estudios sociológicos, Vol. 19, No. 57 (Sep. - Dec., 2001), México, pp. 823-842. Disponível em: https://www.jstor.org/stable/40420691 Último acesso: 30 maio 2021.

PAECHTER, Carrie. Meninos e meninas: aprendendo sobre masculinidades e feminilidades. Tradução: Rita Terezinha Schmidt. Porto Alegre: Artmed, 2009.

PERROT, Michelle. Minha História das Mulheres. Trad. Anela M. S. Correa. 2ed. São Paulo: Contexto, 2015.

QUINTANEIRO, Tania. Processo civilizador, sociedade e indivíduo na teoria sociológica de Norbert Elias. Belo Horizonte: Argvmentum, 2010.

RODE, Renata. Homens pensam com a cabeça de baixo, afirmam especialistas. In: UOL Mulher Comportamento. Disponível em:

https://mulher.uol.com.br/comportamento/noticias/redacao/2010/03/25/home ns-pensam-com-a-cabeca-de-baixo-afirmam-especialistas.htm Último acesso em: 11.mar.2021.

Recebido em: 16 de março de 2021. Aceito em: 31 de maio de 2021. Publicado em: 30 de junho de 2021. 